\title{
High-Performance Polymers and Their Potential Application as Medical and Oral Implant Materials: A Review
}

Wiesli, Matthias Guido ; Özcan, Mutlu

\begin{abstract}
PURPOSE To review the literature on high-performance polymeric (HPP) materials used as medical and oral implants and make comparisons with the commonly used titanium. MATERIAL AND METHODS Original scientific articles published in English in MEDLINE (PubMed-NCBI) and Picarta literature databases between January 01, 1995 and June 01, 2013 were included in this review. Additional information was derived from scientific reports, medical and chemical textbooks, handbooks, product information, manufacturers' instructions, and Internet web sites of the manufacturers. RESULTS Based on the 7 animal studies and 1 clinical study, HPP polyetheretherketone (PEEK) consisting of a single monomer and featuring a low Young modulus may be advantageous. PEEK seems to lead to less osteolyses and healing problems and no scattering in radiation was observed. Some animal studies showed direct contact between PEEK and the bone with high biocompatibility and no evidence for cytotoxicity, mutagenicity, carcinogenicity, and immunogenicity to the present day. CONCLUSION The HPPs (ie, PEEK) may carry some potential to be an alternative material for titanium as medical and dental implants. Yet, clinical and animal studies are limited in the field of implantology with such materials.
\end{abstract}

DOI: https://doi.org/10.1097/ID.0000000000000285

Posted at the Zurich Open Repository and Archive, University of Zurich

ZORA URL: https://doi.org/10.5167/uzh-116037

Journal Article

Accepted Version

Originally published at:

Wiesli, Matthias Guido; Özcan, Mutlu (2015). High-Performance Polymers and Their Potential Application as Medical and Oral Implant Materials: A Review. Implant Dentistry, 24(4):448-57.

DOI: https://doi.org/10.1097/ID.0000000000000285 
High Performance Polymers and their Potential Application as Medical and Oral Implant Materials: A Review

AUTHORS: Matthias Guido Wiesli, MD, M Dent Med*, Mutlu Özcan, DDS, DMD, PhD** ABSTRACT: (183 WORDS)

Purpose: To review the literature on high performance polymeric (HPP) materials used as medical and oral implants and make comparisons with the commonly used titanium.

Material and Methods: Original scientific papers published in English in MEDLINE (PubMedNCBI) and Picarta literature databases between 01/01/1995 and 01/06/2013 were included in this review. Additional information was derived from scientific reports, medical and chemical textbooks, handbooks, product information, manufacturers' instructions, Internet web sites of the manufacturers.

Results: Based on the 7 animals studies and 1 clinical study, high performance polymer Polyetheretherketone (PEEK) consisting of a single monomer and featuring a low Young's modulus may be advantageous. PEEK seems to lead to less osteolyses and healing problems and no scattering in radiation was observed. Some animal studies showed direct contact between PEEK and the bone with high biocompatibility and no evidence for cytotoxicity, mutagenicity, carcinogenicity and immunogenicity to the present day.

Conclusion: The high performance polymers (i.e. PEEK) may carry some potential to be an alternative for Titanium as medical and dental implants. Yet, clinical and animal studies are limited in the field of implantology with such materials.

KEY WORDS: Biocompatibility; high performance polymer; implantology; oral implants; osseointegration; polyetheretherketone (PEEK); Titanium (Ti); Young's modulus

*Dental Student, University of Zürich, Center for Dental and Oral Medicine, Zurich, Switzerland. **Professor, Head of Dental Materials Unit, University of Zürich, Center for Dental and Oral Medicine, Clinic for Fixed and Removable Prosthodontics and Dental Materials Science, Zurich, Switzerland. 
Reprint requests and correspondence to: Mutlu Özcan, $\mathrm{PhD}$, Dental Materials Unit, University of Zürich, Center for Dental and Oral Medicine, Clinic for Fixed and Removable Prosthodontics and Dental Materials Science, Plattenstrasse 11, CH-8032, Zürich, Switzerland.

Phone: +41-44-63-45600 Fax:+41-44-63-44305Ｅ-mail: mutluozcan@hotmail.com 
Titanium (Ti) and its alloys are broadly used as dental and orthopedic implant materials, due to a combination of favorable properties such as high corrosion resistance, biocompatibility, repassivation and adequate mechanical properties. ${ }^{1,2}$ Electrochemically, it is classified as base metal and has a high affinity to oxygen. The corrosion resistance of $\mathrm{Ti}$ and its alloys is a result of spontaneously formed passive oxide films $\left(\mathrm{TiO}_{2}\right)$ when in contact with oxygen. ${ }^{3}$ The Ti surface will be then covered with an oxide film within nanoseconds, yielding to passivation of the metal, protecting the device made of Ti against aggressive attacks and making the surface less reactive. ${ }^{4}$ $\mathrm{TiO}_{2}$ is a stable and dense layer, which acts as a protective barrier to continuous metallic oxidation. This means titanium reveals a high resistance to corrosion. In the event of damage, $\mathrm{TiO}_{2}$ has the ability to spontaneously reform under normal physiological conditions. However, events, such as cyclic loading, implant micromotion, acidic environments and their combined effects, can result in permanent breakdown of the oxide film, which may consequently lead to exposure of the bulk metal to an electrolyte. During this process, a large amount of metal ions and debris are generated of which their accumulation may lead to adverse tissue reactions in the oral environment. ${ }^{5} \mathrm{Ti}$ and its alloys as dental implant material is commonly used and seems to be safe referred to its application. In conjunction with other metals and in an aqueous environment such as the mouth cavity, the passive surface may be impaired and as a consequence lead to osteolysis. ${ }^{6}$ This may cause potential occurrence of neoplasia by metal traces of dental implants. ${ }^{7}$

There are several factors that influence the anchorage of implants in human bone where material type, form, surface and surface chemistry, bone quality play a role in a faster apposition of the bone and eventually osseointegration. ${ }^{8}$ However, potential release of surface coating materials such as hydroxyapatite may induce peri-implantitis. ${ }^{9}$ Another reason for implant-borne infections is the development of biofilm on the Ti surface where the surface texture and physico-chemical surface properties of the implant and the diminished immune-mediated response at the implant-tissue interface are held responsible. The surface protein layer, formed under physiological conditions, is essential for the biocompatibility of $\mathrm{Ti}^{10}$ However, this protein layer may also facilitate the 
colonization of micro-organisms. ${ }^{11} \mathrm{~A}$ biofilm is a cell aggregate where bacteria are adhered to each other and produce extracellular polymers. These extracellular polymers protect the microorganisms against body defence. ${ }^{12}$ Furthermore, antibiotics could hardly destroy the biofilm ${ }^{13}$ meaning that an implant may need to be removed in most cases in order to destroy the biofilm and heal the infection.

Even though $\mathrm{Ti}$ and its alloys acquire many encouraging properties, corrosion happens pathophysiologically when the implant is in contact with the oral fluids. Due to this condition, Ti releases ions (i.e. $\mathrm{Ti}(\mathrm{IV}), \mathrm{V}$ and $\mathrm{Al}$ ) and trigger an immune reaction that is potentially directed towards the implant. The reported immune reaction is part of the type IV reaction. ${ }^{14}$ Another important issue related to the metallic implants is that their presence evokes considerable scattering rays in the field of irradiation. $^{15,16}$

Currently, there are more than 1300 dental implant systems available on the dental market that differ in size, shape and surface characteristics. ${ }^{17}$ Yet, during the last two decades efforts are being made to develop metal-free implants, abutments and restorative materials. One such example is zirconium dioxide. ${ }^{18,19}$ Unfortunately, low temperature degradation and high Young`s modulus are potential disadvantages of this material..$^{20,21}$

The spectrum of applied implant materials in medicine, especially in orthopaedic and traumatic surgery relied mainly on the use of cobalt-chrome alloy, stainless steel or Ti materials by large for pins, plates, screws or total joints. Alternatively, individualized cobalt-chrome implants with titanium plasma spray coatings for talar and tibial or total ankle replacement implant were tried. ${ }^{22}$ However, orthopaedic implants presented similar problems associated with the released metal ions as experienced with oral implants. Osteolysis is a result of wear-induced particles that diffuse within the effective joint space. ${ }^{23}$ The second-generation metal-on-metal bearing couple implants were expected to reduce the osteolysis due to wear of the implants. ${ }^{24}$ Opposite to the expectations, metalon-metal bearing couple implants generated higher number of smaller particles (up to 13.500 times) 
than a metal-on-polyethylene (PE) couple as a result of wear, corrosion and a combination of both. To date, there is no strong evidence of a risk for carcinogenesis or teratogenesis ${ }^{25}$ according to the level of metal ions measured in plasma using spectrometry. ${ }^{26}$

Nonetheless, for the stated reasons above related to the disadvantages of Ti, cobalt-chromium and even zirconium dioxide, metal-free materials namely high performance polymers (HPP) are being proposed as implant materials in medicine. So far, the most commonly used HPP is polyetheretherketone (PEEK) that was first characterized in the 1990s and belongs to the polymer family of polyaryletherketone (PAEK). Soon after its synthesis, it started to be used increasingly in orthopaedic, traumatic surgery and in particular as spine implants. ${ }^{27-29}$ From the biomechanical point of view, reinforced version of PEEK has a similar Young's modulus (18 GPa) with the human cortical bone, which makes it an "isoelastic, implant material. ${ }^{30}$ The possibility of sterilization of PEEK and no scattering under irradiation presented the material as a potential alternative to metallic implants. ${ }^{27}$ Table 1 demonstrates an overview on the classification of commonly used polymers for medical and dental applications.

The objectives of this literature review therefore, were to evaluate the present literature and gain insight into newly developed HPP materials used as medical and oral implants and make comparison with the commonly used titanium. The focus in this literature review will encompass an investigation on chemical, mechanical and biological properties of HPPs and their application in particular in medicine and dentistry as implant materials. Based on the available in vitro, animal and clinical studies, performance of these synthetic materials will be compared with that of titanium. Finally, conclusions will be made whether HPPs could substitute titanium for clinical applications as an implant material or not.

\section{MATERIALS AND METHODS}




\section{Search strategy}

Original scientific papers published in English in MEDLINE (PubMed-NCBI) and Picarta literature databases between 01/01/1995 and 01/06/2013 were included in this review. The following Medical Subject Headings (MeSH), search terms and their combinations were used: ("Dental Implants"[Mesh]) AND ("polytetrafluoroethylene-silicone" [Supplementary Concept] OR "Polytetrafluoroethylene"), ("Polymers"[MeSH]) AND "Dental Implants, Single-Tooth"[MeSH], ("Polymethacrylic Acids"[Mesh]) AND ("Dental Implants"[MeSH] OR "Dental Implants, SingleTooth"[MeSH]), ("Orthopedics"[MeSH]) AND "Prostheses and Implants"[MeSH]) AND "Polymers"[MeSH], "Polymers and material and oral implant", "Fiber-reinforced composite and dental implant", "Fiber reinforced resin and oral implant", "Arthroplasty and titanium", "PEG and dental implant", "Scattering effects and titanium implant", "High performance polymers and PAEK", "High performance polymers and PEEK“, "High performance polymers and PEKK", "High performance polymers and titanium", "High performance polymers and oral implants", "PEEK and titanium", "PEEK and oral implants", "PAEK and titanium" and "PAEK and oral implants". Additional information was derived from scientific reports, medical and chemical textbooks, handbooks, product information, manufacturers`instructions, internet web sites of the manufacturers.

\section{Inclusion / exclusion criteria}

Publications only in English language where full texts were available including abstracts were included. Due to the limited number of studies available, no restrictions were made on study designs. Thus, all experimental, animal and clinical studies were included.

\section{Data extractions}

Two independent reviewers (M.G.W. and M.Ö.) screened the material retrieved from the electronic and hand searched articles for possible inclusion in the review. After initial elimination, based on the titles and the abstracts by both reviewers full-text articles were obtained. In addition, hand 
searches were performed on bibliographies of the selected articles as well as identified narrative reviews to find out whether the search process has missed any relevant article.

\section{RESULTS}

\section{Types and chemistry of high performance polymers}

Among high performance polymers such as PEEG, PEG polysulfone, polybutylene and others, there seems to be more possibilities to create a composite with the pure PEEK biomaterial. Composite materials consist of two or more phases show their own physical, bioactive and mechanical properties. They are bonded together by an interface and the overall mechanical properties are a combination of both materials. PEEK can be reinforced by carbon (carbon fiber-reinforced PEEK = CFR-PEEK) and glass fibers which leads to improved wear resistance and excellent mechanical properties in terms of increased strength and stiffness. ${ }^{28,31-34}$ Also, barium sulfate, a radiopacifier, may be added to PEEK to improve visualization and contrast in imaging. This procedure is often applied in trauma surgery. ${ }^{35}$

The term polymers originate from the Greek word "polumerēs,, and means "having many parts,,. There are many monomers that are arranged in repeating units. If two or more monomers used in a material, it is called copolymer. Furthermore, a polymer may not only be linear but also branched. However, PEEK is comprised of a chain of 100 linear monomer units with an average molecular weight of 80.000 to $120.000 \mathrm{~g} / \mathrm{mol}$. The length and the composition of the molecular chain have a strong influence on the properties on temperature resistance and deformation. There are several possibilities to control physical properties of the material. PEEK or sometimes referred as to polyetherketone (PEK) belongs to the family of polyaryletherketone (PEAK) and is a high performance thermoplastic polymer. PEEK is a linear homopolymer meaning that it consists of only a single monomer (Fig. 1). There are other high-performance polymers on the market such as 
polyetherketone ketone (PEKK) but PEEK is the most commonly used polymer for implants in medical application.

PEEK is synthesized by alkylation of bisphenol salt. The reaction of 4,4'-Difluorobenzophenon with hydrochinon salt is extremely frequent. The presence of the aromatic rings (benzene) gives the molecule a certain stiffness. Nevertheless, the ether (-o-) bond shows another property, namely the molecule is able to rotate in an axillary direction on this position. When the molecule is slowly cooled down from the molten state, there exist two different microstructure phases. On one side, the folded chain gets into ordered domains (crystalline phase) and on the other side, the amorphous phase surrounds the crystals. Thermal processing can control the amount of the crystalline content. The typical quantity in implants is between $30 \%$ and $35 \%$. Even so, it is possible to generate a near amorphous structure by adjusting the cooling rate.

The chemical structure of PEEK presents some outstanding properties such as resistance to chemical and radiation damage, high stability at temperatures above $300^{\circ} \mathrm{C}$ and a greater strength than many metals. The possibility to reinforce PEEK with other materials such as glass or carbon fibers gives this polymer a special quality. This is also a reason why PEEK is used in aircraft industry. However, PEEK is used in medical and dental applications not only because of its stability, biocompatibility, mechanical properties but also for its radiolucency. Pure PEEK has a tan color and is available as pallets or powder. If PEEK is reinforced with carbon fibers to improve strength the color changes into black. ${ }^{27-29}$

\section{Production process of PEEK}

The production of this high-performance thermoplastic polymer in medical or dental implants is a difficult process. PEEK is exceptional in its being a chemical inert material which is very important for implants. Moreover, it is insoluble in all solvents at room temperature. The production process of the major polymer PEAK from the family of HPP is related with high costs in comparison to other 
thermoplastics. There are two different ways to manufacture PEAK. One is the electrophilic reaction where aromatic ether species are linked with ketone groups. The other route is to link the aromatic ketone with an ether bond which is called as nucleophilic displacement reaction. ${ }^{29}$

\section{Electrophilic reaction}

PEAK cannot be synthesized in usual solvents because of its natural resistance toward solubility and tendency to crystallize at a high level. The electrophilic reaction consists of protonating a carbonyl by using anhydrous hydrogen fluoride/boron trifluoride $\left(\mathrm{HF} / \mathrm{BF}_{3}\right)$. This process leads to a high molecular weight polyetherketone (PEK). There are many other electrophilic reactions to produce PEAK. Raychem Ltd. synthesized PEAK in a similar way with alkylthiochloroformates. Friedel Crafts Ltd. polycondensation of 4-(4'-phenoxyphenoxybenzoic acid) in trifluoromethanesulfonic acid. Benzoic acids are substances with reactive end groups of the electrophilic reaction. This means that such agents cannot be manufactured without end-capping in consequence of their thermal instability. The circumstance of high temperature processing would lead to cross-linking of polymers and producing gels. ${ }^{27-29}$

\section{Nucleophilic displacement reaction}

It is very important to use the appropriate solvent to synthesize PEEK due to its reduced solubility. Thermal stability and a resistance towards phenoxide species such as benzophenone or diaphenylsulfone is a relevant feature. However, biphenates are instable to oxidation. For that reason, biphenates are produced in situ by using hydroquinone and sodium or potassium carbonate. A high temperature $\left(>300^{\circ} \mathrm{C}\right)$ is necessary to obtain a high molecular mass. This can be measured by getting an excess of difluorobenzophenone, which is formed, to fluorine-terminated chain. The described method is often used in the industry and presents the ability to produce many different variants of the PEAK family such as PEK, PEEK, PEKK, PEKEKK and so on. The often used polymer of the PEAK family PEEK merges into glass at a temperature of about $143^{\circ} \mathrm{C}$ and presents a crystalline melt transition temperature of about $343^{\circ} \mathrm{C} .{ }^{27-29}$ 


\section{Young's modulus and yield stress of PEEK}

PEEK presents different mechanical properties than metal devices such as $\mathrm{Ti}$, its alloys and $\mathrm{Co}-\mathrm{Cr}$ because of its structure and process of production. Unfilled PEEK has a Young's modulus between 3 and $4 \mathrm{GPa}^{28,32,36}$ The young's modulus of PEEK can be increased from $19 \mathrm{GPa}$ to $150 \mathrm{GPa}$ with additives such as carbon fiber. ${ }^{34}$ Table 2 shows the Young's modulus of different forms of titanium, PEEK, Cr-Co and bone.

\section{Osseointegration of PEEK}

Osteointegration or biocompatibility is the interaction between the biomaterial and the ambient tissue. Each tissue of the body is different. Blood makes another interaction with PEEK in comparison to bone. Pure PEEK polymers appear in a bulk form as an inert material. There is no observed adverse effect such as releasing ions. Bioactivity means a positive interaction with tissues and leads to a differentiation of cells. PEEK is not known as a bioactive material. Nevertheless, there results a direct contact between PEEK and the human bone. Toth et al. showed in their study the histologic fusion between PEEK cages packed with autograft or rhBMP-2 and bone of sheep after six month. There was no evidence of degradation or wear debris. ${ }^{36}$ However, there was no chemical bond between PEEK devices and bone implying that there were only micromechanical interlocks. ${ }^{36}$ If there evolves no histological fusion between PEEK and bone, it occurs a pseudoarthrosis. These phenomena caused of relative motion between the device and the bone refers to debris around the implant in tissue. The result is an inflammatory response with macrophages and other immune cells such as lymphocytes and plasma cells, which may be followed by a chronic inflammation. $^{29}$

PEEK was also tried to be coated with hydroxyapatite (HA) in an attempt to increase the cell attachment to the implant surface. Such a coating presented promising results compared with uncoated PEEK. ${ }^{28,37}$ 


\section{PEEK Allergy}

Kratzer et al. investigated mutagenicity and cytotoxicity of PEEK in an animal study. ${ }^{38}$ There was no evidence of mutagenicity and cytotoxicity on the human organism from PEEK braid, its ethanol or chloroform extracts under the appropriate conditions in their report. Similarly, carbon-fibre reinforced PEEK did not show any adverse reactions. ${ }^{38}$ In another study, Wenz et al. investigated the biocompatibility of PEEK focusing on cytotoxicity. ${ }^{39}$ There was also no evidence of cytotoxicity, mutagenicity, carcinogenicity and immunogenicity of PEEK and its composites in a bulk form. ${ }^{29}$ Another research group evaluated the influence of PEEK-Optima ${ }^{\circledR}$, ultra-high molecular weight polyethylene (UHMWPE) and cross-linked UHMWPE (X-UHMWPE) with three different particle sizes $(0.7 \mu \mathrm{m}, 2 \mu \mathrm{m}$ and $10 \mu \mathrm{m})$ at the dose of 20 particles per cell on monocytes and macrophages after $24 \mathrm{~h}$ and $48 \mathrm{~h}$. Different assays and cytokine analysis (IL-1b, IL-6, IL-8, MCP-1 and TNF- $\alpha$ ) did not present a significant differences on viability or proliferation between the three different materials. PEEK-Optima ${ }^{\circledR}$ showed less cytoxicity response compared with UHMWPE and X-UHMWPE, after $24 \mathrm{~h}$ and $48 \mathrm{~h}$. The highest reaction was observed at particle size of $0.7 \mu \mathrm{m}$. Particles of X-UHMWPE presented significantly more IL-1b, IL-6, MCP-1 and TNF- $\alpha$ at $24 \mathrm{~h}^{40}$

This literature review revealed 7 animal studies ad 1 clinical study using HPPs:

\section{Animal studies with PEEK}

\section{Osseointegration and infection}

Cook and Rust-Dawicki investigated the interface attachment strength between PEEK and the unicortical bone in four mongrel dogs. They placed overall forty titanium-coated and uncoated cylindrical implants of PEEK in unicortical site of the femurs. ${ }^{41}$ The implants were examined mechanically and histologically after sacrificing the animals. Bone contact, porosity, bone ingrowth, inflammatory response and mode of failure after four and eight weeks were the parameters of interest. The uncoated implants showed significantly higher interfacial shear strength after four 
weeks. There was no difference between the uncoated and coated implants after eight weeks. However, the titanium-coated materials presented significantly higher percentage of bone contact at both time-points. $^{41}$

Nakahara et al. pursued a similar approach. ${ }^{34}$ They compared CFR/PEEK cups and stems with hydroxyapatite (HA) coatings for cementless hip prostheses and without HA for cement fixation in sixteen sheep. Each animal received a unilateral total hip replacement. The follow-up was up to fifty-two weeks. Overall five cementless cups and stems as well as six cemented cups and stems were radiographically and histologically investigated. Five sheep were excluded because of early complications. They indicated that cementless as well as cemented CFR/PEEK fixation presented a good stability in the bone. A difference was found in the cup fixation because the attachment was difficult in both types. In two cases, the bone on-growth in the cementless cups were observed initially. In another study of Nakahara et al., they compared the bone on-growth fixation of surface roughened, bioactive and uncemented CFR-PEEK stems and titanium (Ti6Al4V) stems in twelve bovines. $^{42}$ Each animal received a unilateral hemiarthroplasty of the hip. The follow up period was twelve months. Titanium stems were applied as a control. Three bovines limped and were sacrificed within the first four weeks. All cases with titanium stem and two cases with CFR-PEEK presented bone on-growth fixation of the remaining animals. Osteopenia was observed in three of five cases of the titanium stem but not in the CFR-PEEK cases.

Besides the osteointegration, the incidence of bacterial infection is an important aspect in implantology. Webster et al. investigated this aspect in silicon nitride $\left(\mathrm{Si}_{3} \mathrm{~N}_{4}\right)$ and the results with PEEK and titanium implants. ${ }^{43}$ All three different materials were implanted in calvarial defects of ninety-six rats following of injection of $1 \times 10^{4}$ Staphylococcus epidermidis and saline at the control group. Four rats were killed and examined of the quantity of bone formation and presence of bacteria after $3,7,14$ days and 3 months. About $64 \%$ of $\mathrm{Si}_{3} \mathrm{~N}_{4}, 24 \%$ of PEEK and $36 \%$ of titanium showed a new bone formation with absence of bacteria injection 3 months after surgery. $\mathrm{Si}_{3} \mathrm{~N}_{4}$ 
demonstrated $41 \%$, titanium $26 \%$ and PEEK $21 \%$ bone formation in presence of bacteria. Briefly, $\mathrm{Si}_{3} \mathrm{~N}_{4}$ presented a significantly better new bone formation and resistance to bacterial infection in contrast to titanium and PEEK. ${ }^{43}$

$\mathrm{Wu}$ et al. evaluated the bioactivity of different amounts of nano- $\mathrm{TiO}_{2}\left(\mathrm{n}-\mathrm{TiO}_{2}\right)$ and PEEK powder. ${ }^{44}$ The resulting powder mixture $\left(\mathrm{n}-\mathrm{TiO}_{2} / \mathrm{PEEK}\right)$ was placed in a specially manufactured mould disk $(15 \times 2 \mathrm{~mm})$ for physical, chemical characterization and in vitro testing and cylindrical implants $(4 \times 7$ $\mathrm{mm}$ ) for in vivo testing. PEEK acted as a control. Scanning, transmission electron microscopy and X-ray photoelectron spectroscopy was used to analyze the surface and dispersion in the composites. There was more cell attachment at the rough n- $\mathrm{TiO}_{2} / \mathrm{PEEK}$ while the smooth PEEK presented significantly lower optical density. The authors used three beagle dogs for the in vivo examination. Two implants of PEEK and n- $\mathrm{TiO}_{2} / \mathrm{PEEK}$ were placed on each tibia of the animals. The dogs were sacrificed after 4 weeks. PEEK showed almost half of the percent bone volume value compared with $\mathrm{n}-\mathrm{TiO}_{2} / \mathrm{PEEK}(\mathrm{p}<0.05){ }^{44}$

\section{Biocompatibility}

In the orthopaedic spine surgery, the use of PEEK is often described. In an animal study with thirteen sheep, Toth et al. evaluated a radiolucent PEEK-threaded interbody cages which was filled with autograft $(n=7)$ or rhBMP-2 $(n=6)$ on an absorbable collagen sponge. ${ }^{36}$ The fusion was investigated with blinded radiographic, biomechanic, histologic and statistical procedures after 6 months. The authors observed no device degradation or wear debris at the PEEK cages. Only a mild chronic inflammation with few macrophages around the peri-implant tissue was demonstrated. ${ }^{36}$

\section{Mechanical properties}

Rohner et al. compared the performance of CFR/PEEK radiolucent plate (snake plate (SP)) with high stiffness and fixed angle converging screws with a seven-hole titanium Locking Compression Plate (LCP). ${ }^{45}$ They used eighteen sheep where an osteotomy in a tibia was performed and stabilized 
with a SP $(n=6)$ or a LCP $(n=6)$. They measured the callus dimension with X-ray in each group after zero, two, four, six and eight weeks. The animals were killed after eight weeks and they measured in pairs the torsion to determine strength and stiffness in the osteomized and contralateral tibiae. There was no significant difference between the osteomized and non-osteomized tibia. The authors calculated the median value for relative reduction of strength (100x (operated - contralateral) / contralateral). The strength for the SP group was $-13.93 \%$ and $-7.49 \%$ for the LCP group. The stiffness showed similar values in both groups (SP group: $-24.44 \%$ and LCP group: $-27.08 \%$ ). Rohner et al. used the six remaining sheep for a second experiment. They evaluated the initial vascular disturbance after plate insertion. In this experiment there was also no significant disturbance in periosteal circulation.

\section{Clinical Studies}

\section{Osseointegration}

Chou et al. investigated fifty-five patients who received a segmental anterior discectomy with a follow-up period of up to twelve months. ${ }^{46}$ They formed three groups: Group A $(n=27)$ received implants of a titanium cage packed with biphasic calcium phosphate ceramic, Group B (n=9) was operated with PEEK cages containing Triosite and Group $\mathrm{C}$ received autogenous tricortical iliac crest bone graft. There were two radiographically fusion rates after six and twelve months. After six months, Group A: 37.21\%, Group B: 93.3\% and Group C: $84.85 \%$. After twelve months, Group A : 46.51\%, Group B and C 100\% fusion rates (Table 4). ${ }^{46}$

There was no randomized control clinical trial found at the time of this review.

\section{DISCUSSION}

In this review, only seven animal studies and one clinical study could provide information on the question whether PEEK material could be an alternative to Ti implants. Although Ti shows many 
advantages and is a well-tolerated metal, investigations continue to eliminate metals from dentistry and replace them with more inert non-metallic materials.

From the biomechanical point of view, Rohner et al. investigated the stiffness and strength of radiolucent CFR-PEEK plate and a titanium plate for osteosynthesis in a sheep model with the outcome that both materials presented similar mechanical properties. ${ }^{45}$ This study also indicated that CFR-PEEK is not only an excellent osteosynthesis material but it also does not produce artefacts in radiographical examinations. PEEK having Young`s modulus with 10 to $30 \mathrm{GPa}$ closer to human bone may have better implications in terms of less marginal bone resorption and osteolysis as opposed to titanium and zirconia.

Investigation in spinal surgery using $\mathrm{PEEK}^{28,47}$ as well as dental implants ${ }^{31,41}$ indicated high biocompatibility, no evidence of cytotoxicity, mutagenicity, carcinogenicity and immunogenicity. ${ }^{28}$ The animal study of Toth et al. described a good biocompatibility without device degradation and wear debris of the PEEK cages. ${ }^{36}$ Although the follow-up time of the experiment was relatively short, authors claimed that there was an indication of PEEK being a substitute for titanium-based implants considering the radiographic, biomechanical and histological results.

Currently bone nails which are used as osteosynthesis material for bone fractures, are made of PEEK. However, this review did not find its application in dental implantology to qualify the material as an oral implant. Any releasing of ions or debris of PEEK is not known. Nanometer-sized particles generated as a consequence of wearing of the metal implant surface are potential factors for osteolysis and may influence of the implant longevity. ${ }^{25}$ These aspects need further investigation with HPPs.

According to the results of animal studies, excellent osseointegration of coated carbon fiber reinforced $\mathrm{PEEK}^{34,41}$ were comparable with titanium. ${ }^{42}$ This indicates that potential coatings may be 
needed for CFR/PEEK to make it a realistic alternative to titanium for medical and dental implants. Nakahara et al. could show in their study that no osteopenia has occurred in CFR-PEEK stems compared with the titanium stems. ${ }^{42}$ This may be a further advantage of this HPP. In terms of bacterial infection, PEEK has a less biofilm resistance effect compared with silicon nitride $\left(\mathrm{Si}_{3} \mathrm{~N}_{4}\right)$ and titanium. ${ }^{43}$ This suggests that PEEK implant with a bacterial infection would need an antibiotic therapy over a long time which may have a negative consequence of the general health concerning of the antibiotic resistance difficulty.

It could be easily conceivable that not only implants consist of HPP but also the abutments. In a recent study, the influence of titanium and polymer abutments had favorable effect on the soft and hard tissues. They observed an effect of bone and soft tissue level. ${ }^{48}$ However, there would not be any mechanical and chemical interactions between two different materials if implant and its abutment consisted of the same chemical structure.

HPP could play a role not only for medical and dental implants but also in the reconstructive surgery. Von Wilmowsky et al. examined the influence of laser sintered PEEK with incorporated nano-sized carbon black, $\beta$-tricalcium phosphate $(\beta$-TCP) and bioactive glass $45 \mathrm{~S} 5$ on human osteoblasts (hFOB 1.19). ${ }^{49}$ The highest proliferation rate of osteoblasts showed the bioactive glass containing sintered PEEK at day 7 (OD 1.76 +/-0.22) and at day 14 (OD $3.75+/-0.31$ ) compared with pure PEEK as the control group. These results presented that laser sintered PEEK would be a reasonable alternative to bone substitute for reconstructive surgery. ${ }^{49}$ Another research group coated the surface of PEEK with titanium by using an electron beam with the objective of evaluating biocompatibility and adhesion to bone tissue. The study showed a considerable higher bone contact of titanium coated PEEK compared with pure PEEK. ${ }^{50}$ Furthermore, there is need for more investigations concerning contact stress and wear of HPP materials. That would lead to a better understanding of the mechanical characterization. ${ }^{51}$ Although PEEK seemed to have excellent 
properties and be considered as an alternative material to titanium, cobalt-chrome and other materials, there is more research needed.

\section{CONCLUSIONS}

Metallic implant materials and in particular Titanium and its alloys, continue to be the materials of choice for medical and dental implantology because of their biocompatibility, resistance to corrosion and mechanical properties. Despite of their advantages, these materials implicate some issues such as osteolysis followed by implant failure, scattered radiation, occasional hypersensitivity, allergy and possibly surface degradation related to peri-implantitis. A non-metallic material such as high performance polymer polyetheretherketone (PEEK) seems to have favorable properties. Yet, the numbers of experimental, animal and clinical studies were limited to make conclusions for their medical and dental utilization.

\section{DISCLOSURE}

The authors claim to have no financial interest, either directly or indirectly, in the products or information listed in the paper.

Author contributions: Designed the study: MÖ. Performed experiments: MGW, MÖ. Wrote the paper: MGW, MÖ.

Funding: The authors have no support or funding to report. 


\section{REFERENCES}

1. Lautenschlager EP, Monaghan P. Titanium and titanium alloys as dental materials. Int Dent J. $1993 ; 43: 245-253$.

2. Renouard F, Nisand D. Impact of implant length and diameter on survival rates. Clin Oral Implants Res. 2006;17:35-51.

3. Long M, Rack HJ. Titanium alloys in total joint replacement-a materials science perspective. Biomaterials. 1998;19:1621-1639.

4. Milosev I, Metikos-Huković M, Strehblow HH. Passive film on orthopaedic TiAlV alloy formed in physiological solution investigated by X-ray photoelectron spectroscopy. Biomaterials. 2000;21:2103-2013.

5. Mouhyi J, Dohan DM, Albrektsson T. The peri-implantitis: implant surfaces, microstructure, and physicochemical aspects. Clin Implant Dent Relat Res. 2012;14:170-183.

6. Dorr LD, Bloebaum R, Emmanual J, et al. Histologic, biochemical, and ion analysis of tissue and fluids retrieved during total hip arthroplasty. Clin Orthop Relat Res. 1990;261:82-95.

7. Poggio CE. Plasmacytoma of the mandible associated with a dental implant failure: a clinical report. Clin Oral Implants Res. 2007;18:540-543.

8. Wheeler SL. Eight-year clinical retrospective study of titanium plasma-sprayed and hydroxyapatite-coated cylinder implants. Int J Oral Maxillofac Implants. 1996;11:340-350.

9. Albrektsson T, Wennerberg A. Oral implant surfaces: Part 1--review focusing on topographic and chemical properties of different surfaces and in vivo responses to them. Int J Prosthodont. $2004 ; 17: 536-543$.

10. Zhao L, Chu PK, Zhang Y, et al. Antibacterial coatings on titanium implants. J Biomed Mater Res B Appl Biomater. 2009;91:470-480.

11. Hetrick EM, Schoenfisch MH. Reducing implant-related infections: active release strategies. Chem Soc Rev. 2006;35:780-789.

12. da Silva EP, De Martinis EC. Current knowledge and perspectives on biofilm formation: the case of Listeria monocytogenes. Appl Microbiol Biotechnol. 2013;97:957-968. 
13. Römling U, Balsalobre C. Biofilm infections, their resilience to therapy and innovative treatment strategies. J Intern Med. 2012;272:541-561.

14. Schalock PC, Menné T, Johansen JD, et al. Hypersensitivity reactions to metallic implants diagnostic algorithm and suggested patch test series for clinical use. Contact Dermatitis. 2012;66:419.

15. Ozen J, Dirican B, Oysul K, et al. Dosimetric evaluation of the effect of dental implants in head and neck radiotherapy. Oral Surg Oral Med Oral Pathol Oral Radiol Endod. 2005;99:743-747.

16. Friedrich RE, Todorovic M, Krüll A. Simulation of scattering effects of irradiation on surroundings using the example of titanium dental implants: a Monte Carlo approach. Anticancer Res. 2010;30:1727-1730.

17. Lesmes D, Laster Z. Innovations in dental implant design for current therapy. Oral Maxillofac Surg Clin North Am. 2011;23:193-200.

18. Nakamura K, Kanno T, Milleding P, et al. Zirconia as a dental implant abutment material: a systematic review. Int J Prosthodont. 2010;23:299-309.

19. Özkurt Z, Kazazoğlu E. Zirconia dental implants: a literature review. J Oral Implantol. $2011 ; 37: 367-376$.

20. Akagi K, Okamoto Y, Matsuura T, et al. Properties of test metal ceramic titanium alloys. $J$ Prosthet Dent. 1992;68:462-467.

21. Kelly JR, Denry I. Stabilized zirconia as a structural ceramic: an overview. Dent Mater. 2008;24:289-298.

22. Zartman KC, Berlet GC, Hyer CF, et al. Combining dissimilar metals in orthopaedic implants: revisited. Foot Ankle Spec. 2011;4:318-323.

23. Schmalzried TP, Jasty M, Harris WH. Periprosthetic bone loss in total hip arthroplasty. Polyethylene wear debris and the concept of the effective joint space. J Bone Joint Surg Am. 1992;74:849-863.

24. Weber BG. Experience with the Metasul total hip bearing system. Clin Orthop Relat Res. 1996;329: S69-77. 
25. Delaunay C, Petit I, Learmonth ID, et al. Metal-on-metal bearings total hip arthroplasty: the cobalt and chromium ions release concern. Orthop Traumatol Surg Res. 2010;96:894-904.

26. Barry J, Lavigne M, Vendittoli PA. Evaluation of the method for analyzing chromium, cobalt and titanium ion levels in the blood following hip replacement with a metal-on-metal prosthesis. $J$ Anal Toxicol. 2013;37:90-96.

27. Eschbach L. Nonresorbable polymers in bone surgery. Injury. 2000;31:22-27.

28. Kurtz SM, Devine JN. PEEK biomaterials in trauma, orthopedic, and spinal implants. Biomaterials. 2007;28:4845-4869.

29. Kurtz SM. PEEK Biomaterials Handbook. 225 Wyman Street, Waltham, MA 02451, USA: Elsevier Science 2012:30-31.

30. Skinner HB. Composite technology for total hip arthroplasty. Clin Orthop Relat Res. 1988;235:224-236.

31. Lee WT, Koak JY, Lim YJ, et al. Stress shielding and fatigue limits of poly-ether-ether-ketone dental implants. J Biomed Mater Res B Appl Biomater. 2012;100:1044-1052.

32. Devine DM, Hahn J, Richards RG, et al. Coating of carbon fiber-reinforced polyetheretherketone implants with titanium to improve bone apposition. J Biomed Mater Res $B$ Appl Biomater. 2013;101:591-598.

33. Grupp TM, Giurea A, Miehlke RK, et al. Biotribology of a new bearing material combination in a rotating hinge knee articulation. Acta Biomater. 2013;9:7054-7063.

34. Nakahara I, Takao M, Bandoh S, et al. In vivo implant fixation of carbon fiber-reinforced PEEK hip prostheses in an ovine model. J Orthop Res. 2013;31:485-492.

35. Clarke IC, Donaldson T, Bowsher JG, et al. Current concepts of metal-on-metal hip resurfacing. Orthop Clin North Am. 2005;36:143-162.

36. Toth JM, Wang M, Estes BT, et al. Polyetheretherketone as a biomaterial for spinal applications. Biomaterials. 2006;27:324-334.

37. Rabiei A, Sandukas S. Processing and evaluation of bioactive coatings on polymeric implants. $J$ Biomed Mater Res A. 2013;101:2621-2629. 
38. Katzer A, Marquardt H, Westendorf J, et al. Polyetheretherketone-cytotoxicity and mutagenicity in vitro. Biomaterials. 2002;23:1749-1759.

39. Wenz LM, Merritt K, Brown SA, et al. In vitro biocompatibility of polyetheretherketone and polysulfone composites. J Biomed Mater Res. 1990;24:207-215.

40. Hallab NJ, McAllister K, Brady M, et al. Macrophage reactivity to different polymers demonstrates particle size- and material-specific reactivity: PEEK-OPTIMA ${ }^{\circledR}$ particles versus UHMWPE particles in the submicron, micron, and 10 micron size ranges. $J$ Biomed Mater Res $B$ Appl Biomater. 2012;100B:480-492.

41. Cook SD, Rust-Dawicki AM. Preliminary evaluation of titanium-coated PEEK dental implants. J Oral Implantol. 1995;21:176-181.

42. Nakahara I, Takao M, Bandoh S, et al. Novel surface modifications of carbon fiber-reinforced polyetheretherketone hip stem in an ovine model. Artif Organs. 2012;36:62-70.

43. Webster TJ, Patel AA, Rahaman MN, et al. Anti-infective and osteointegration properties of silicon nitride, poly(ether ether ketone), and titanium implants. Acta Biomater. 2012;8:4447-4454.

44. Wu X, Liu X, Wei J, et al. Nano-TiO2/PEEK bioactive composite as a bone substitute material: in vitro and in vivo studies. Int J Nanomedicine. 2012;7:1215-1225.

45. Rohner B, Wieling R, Magerl F, et al. Performance of a composite flow moulded carbon fibre reinforced osteosynthesis plate. Vet Comp Orthop Traumatol. 2005;18:175-182.

46. Chou YC, Chen DC, Hsieh WA, et al. Efficacy of anterior cervical fusion: comparison of titanium cages, polyetheretherketone (PEEK) cages and autogenous bone grafts. J Clin Neurosci. 2008;15:1240-1245.

47. Niu CC, Liao JC, Chen WJ, et al. Outcomes of interbody fusion cages used in 1 and 2-levels anterior cervical discectomy and fusion: titanium cages versus polyetheretherketone (PEEK) cages. J Spinal Disord Tech. 2010;23:310-316.

48. Koutouzis T, Richardson J, Lundgren T. Comparative soft and hard tissue responses to titanium and polymer healing abutments. J Oral Implantol. 2011;37:174-182. 
49. von Wilmowsky C, Vairaktaris E, Pohle D, et al. Effects of bioactive glass and beta-TCP containing three-dimensional laser sintered polyetheretherketone composites on osteoblasts in vitro. J Biomed Mater Res A. 2008;87:896-902.

50. Han CM, Lee EJ, Kim HE, et al. The electron beam deposition of titanium on polyetheretherketone (PEEK) and the resulting enhanced biological properties. Biomaterials. 2010;31:3465-3470.

51. Albert K, Schledjewski R, Harbaugh M, et al. Characterization of wear in composite material orthopaedic implants. Part II: The implant/bone interface. Biomed Mater Eng. 1994;4:199-211. 


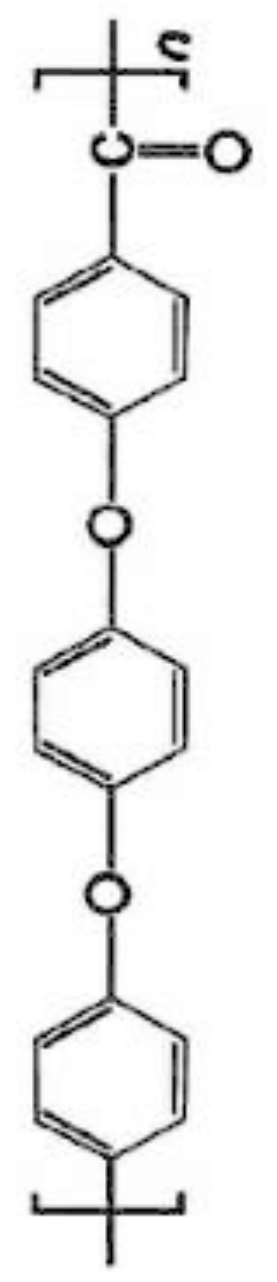




\section{LEGENDS}

Table 1. Classification of major conventional and high performance polymers used for medical and dental applications.

Table 2. Young's modulus of different implant materials.

Table 3. Summary of findings of animal studies using high performance polymer PEEK as an implant material.

Table 4. Summary of findings of clinical studies using high performance polymer PEEK as an implant material.

Fig. 1. Chemical formula of poly(aryl-ether-ether-ketone), commonly abbreviated as PEEK. The molecule is relatively stiff due to the presence of the aromatic (benzene) rings in its backbone. At the same time, the molecule does have the freedom to rotate axially around the esther (-O-) and ketone-carbon bonds (-CO-). 